\title{
Eco-Packaging Campaign through Motion Graphic
}

\author{
Haekal Muhammad ${ }^{1}$, Wirania Swasty ${ }^{2}$ \\ ${ }^{1,2}$ Visual Communication Design, Telkom University, Bandung, Indonesia \\ haekalmuham8@gmail.com (Haekal Muhammad),wirania@telkomuniversity.ac.id (Wirania Swasty)
}

\begin{abstract}
Nowadays, the use of food packaging is inseparable from food products. Today many food and beverage sellers still use hazardous food packaging (e.g. styrofoam) to reduce production cost but they do not aware of its negative effects. Local government especially Bandung has banned the use of styrofoam materials and urge to replace food packaging with materials that are environmentally friendly and safe for human health. The problem identified is the lack of understanding of both sellers and consumers about the packaging that has a bad impact on the environment and health. It needs a specific information media confirms about the hazardous packaging. This study begins with a literature study on eco-packaging followed by observations to household food sellers. Interviews and questionnaires were conducted to support the study. As a result, the information conveyed using the elements of motion and information is easier to understand. This is supported by the finding that many people spend their spare time watching movies or videos. $40 \%$ of respondents stated that billboards or videotrons are the right medium to convey messages to the society. The aim of this study is to provide information on eco-packaging through video campaign. By this study, it is expected to educate the society as food packaging buyers and consumers.
\end{abstract}

Keywords campaign, eco-packaging, video

\section{Introduction}

Nowadays, the use of food packaging is inseparable from food products. Today many food and beverage sellers still use hazardous food packaging (e.g. styrofoam) to reduce production cost but they do not aware of its negative effects. Local government especially Bandung has banned the use of styrofoam materials and urge to replace food packaging with materials that are environmentally friendly and safe for hu-man health. The problem identified is the lack of under-standing of both sellers and consumers about the packaging that has a bad impact on the environment and health. Moreover, there is lack of reminding media, specific in-formation and campaign regarding packaging that human and environmental friendly. It needs a specific information media confirms about the hazardous packaging and provide an understanding of packaging that is safe for health and the environment. The aim of this study is to provide information on eco-packaging through video campaign. By this study, it is expected to educate the society as food packaging buyers and consumers.

\section{Theoretical review}

\subsection{Eco-Packaging}

Although the main function of the packaging is to protect the product/ its content, it should be focused on the undesirable effects of its material. Reduction in the amount of packaging material can be made to reduce the waste which can readily biodegradable, reusable and non-toxic [1].

The Resource Conservation and Recovery Act (RCRA) was issued in October 1976 with the following objectives [2]:

1. Reduce waste and promote efficient and sustainable use of natural resources.

2. Prevent the use of harmful substances to humans and ecosystems.

3. Waste management and cleaning of chemical contamination in a safe and environmentally friendly manner.

\subsection{Social Change Campaign}

Campaigns can be defined as the use of different communication methods in a coordinated manner over a period of time aimed at directing audiences on specific issues and their solutions [3].

Cause Oriented Campaigns is a goal-oriented campaign that is specific to social change. This type of campaign is referred to as social change campaigns - which aimed at addressing social issues through changing attitudes and public behaviour.

\subsection{Motion Graphic}

Manovich (2013 in ref 4) argues that "motion graphics is a dynamic part of contemporary culture". Designing to engage a television audience involves a new language of motion 
graphics. It is a postmodern approach to branding that seeks to engage the consumer's senses and emotions [4].

Compared to static infographics, motion graphics attract more people in different ways emotionally (through music and moving images). It is able to communicate the message in order to create a visual and emotional allure that persuades viewers in various circles [5]

\section{Methods}

This study used qualitative and quantitative approach. This study began with literature studies on eco-packaging and the dangers of using styrofoam and plastics. Afterward, observation was conducted to several locations, especially to Small and Medium Enterprises (SMEs) and buyers of food or beverage packaging. The observed data obtained will then be analyzed using a comparison matrix. The questionnaire is addressed to some elements of the community, including sellers and buyers, who aim to obtain in-depth information about packaging knowledge. This questionnaire addressed to find out common insight about environmentally friendly packaging, public opinion on the role of local government in enforcing regional regulations on hazardous packaging, and public opinion about the concept of effective information media for extension. The result data from the questionnaire is then done by cross tabulation. The questionnaire was also conducted as a pilot study to determine the right medium for the campaign.

Questionnaires were distributed to 100 respondents in Bandung and surrounding areas (Table 1). Respondents' profession has been determined to facilitate the collection of data with the distribution of $35 \%$ of students, $35 \%$ of SME sellers, and $30 \%$ of workers.

Table 1. Respondents Data

\begin{tabular}{|l|l|c|}
\hline \multicolumn{2}{|c|}{ Demographics } & $\begin{array}{c}\text { Frequency/ } \\
\text { Percentage }\end{array}$ \\
\hline \multirow{3}{*}{ Gender } & Male & 73 \\
\cline { 2 - 3 } & Female & 27 \\
\hline \multirow{2}{*}{ Age } & Under 20 y.o & 16 \\
\cline { 2 - 3 } & $21-30$ y.o & 46 \\
\cline { 2 - 3 } & 30 y.o above & 38 \\
\hline \multirow{3}{*}{ Occupation } & Students & 35 \\
\cline { 2 - 3 } & Sellers & 35 \\
\cline { 2 - 3 } & Employees & 30 \\
\hline \multirow{3}{*}{$\begin{array}{l}\text { Social Economic Status } \\
\text { (SES) }\end{array}$} & $\mathrm{A}$ & 9 \\
\cline { 2 - 3 } & $\mathrm{B}$ & 64 \\
\cline { 2 - 3 } & $\mathrm{C}$ & 27 \\
\hline
\end{tabular}

Furthermore, interviews were conducted with various packaging experts and some sellers and buyers who used food and beverage packaging. The interviewees are personnel of Bandung Environment and Hygiene Department which has a big role on packaging handling in Bandung city, packaging producer that can give information about purchasing power of packaging every day, seller that give information about the use of the packaging, and buyer who can provide information about their attractiveness of packaging. These interviewees will be asked questions about the most effective packaging, means, and media used for packaging. The result of this interview is done by qualitative approach analysis.

\section{Result and Discussion}

\subsection{Finding}

Based on observation, the use of styrofoam for primary packaging; which is directly in contact with food and beverages is still often found in many places. Not only styrofoam, but there are used paper and plastic bags as a primary packaging. Without realizing that the ink contained from waste paper and harmful substances contained in plastic will be bad for health.

The interview was conducted with Septriadi Pratama from the Water Pollution Control Unit (PPA) who has a task in handling styrofoam packaging. He said that the counseling of packaging is done in all urban villages and sub-districts through stickers, t-shirts, and social media of Bandung mayor. He also conducts counseling to several schools and campuses in Bandung. Various programs conducted in the approach to the community to introduce eco-packaging has been done.

Campaign through motion graphic could be efective depends on target audiences. In addition, it needs the supporting media such as stickers, posters, T-shirts and social media [6].

Another interviee agrees that carton material can be quite expensive but clearly environmental friendly. Consumers want packaging that is cheap, healthy and safe. He also agrees and recommends the use of eco-packaging or can also bring food containers from home. Consumer lifestyle is also very influential on the determination of packaging from SME sellers.

He agrees campaign through motion graphic, however it needs supporting media and a strong agency in getting the audience. He agrees if the megatron is effective as a medium for motion graphics. He also suggests to prioritize in changing the mindset of consumers to change the behaviour of sellers. Videos content should be about the impact of packaging, the victim of the packaging then to persuade the target audiences [7].

From the questionnaire, it was revealed that plastic became the most commonly used as packaging by the respondents, followed by styrofoam and cans. Plastics are often used by respondents who have monthly expenses of about 1 to 3 million (SES B). Plastics are most often used by some students for food or beverage containers, SME sellers who simplify their use as packaging, and workers as food and beverage containers.

Most respondents simply know the negative impact of the hazardous packaging but can not mention the impact to be gained. Respondents only know that there are already government regulations on the dangerous packaging but can not mention the laws that prohibit and sanction that will be accepted. Lack of information given by the local government, so there is no information media that explains about eco-packaging. 
40 Respondents (40\%) assume that the most appropriate and effective media for eco-packaging is to use billboards or megatron screens so that many people can see and receive the content of the information provided. In other words, information can be delivered to the target audience of a large number.

\subsection{Communication and Visual Concept}

The concept of a message in the motion graphic video will provide an explanation of the overall eco-friendly packaging and health, from introducing eco-packaging, ecofriendly packaging comparison and vice versa, impacts to be gained, and solutions to be made. The introduction of eco-packaging begins with the understanding, rules, and content. The packaging comparison begins with unsafe packaging for the environment and then the packaging that should be used. Then an explanation of the adverse effects of environmental and health and the solution that should be used and done.
The big idea is Eco-Packaging Campaign, Environmentally Friendly and Health to explain that hazardous packaging could have an impact on the environment and human health. Adverse impacts are often experienced by the community so that the need information about ecopackaging. The video will introduce and provide solutions on packaging that is human and environmental friendly.

In this video, it will use visual styling animation 2dimensional infographics. Using animation greatly facilitates the audience to understand as well as describe the meaning of campaign. The use of infographics is to simplify the information into dynamic images that appeal to audiences. 2-Dimensions are selected so as not to make it difficult for the gallery to understand the message content. The graphic style used is flat design.

The main character in this animation is a teenager who wants to know various things about the use of packaging around Bandung.
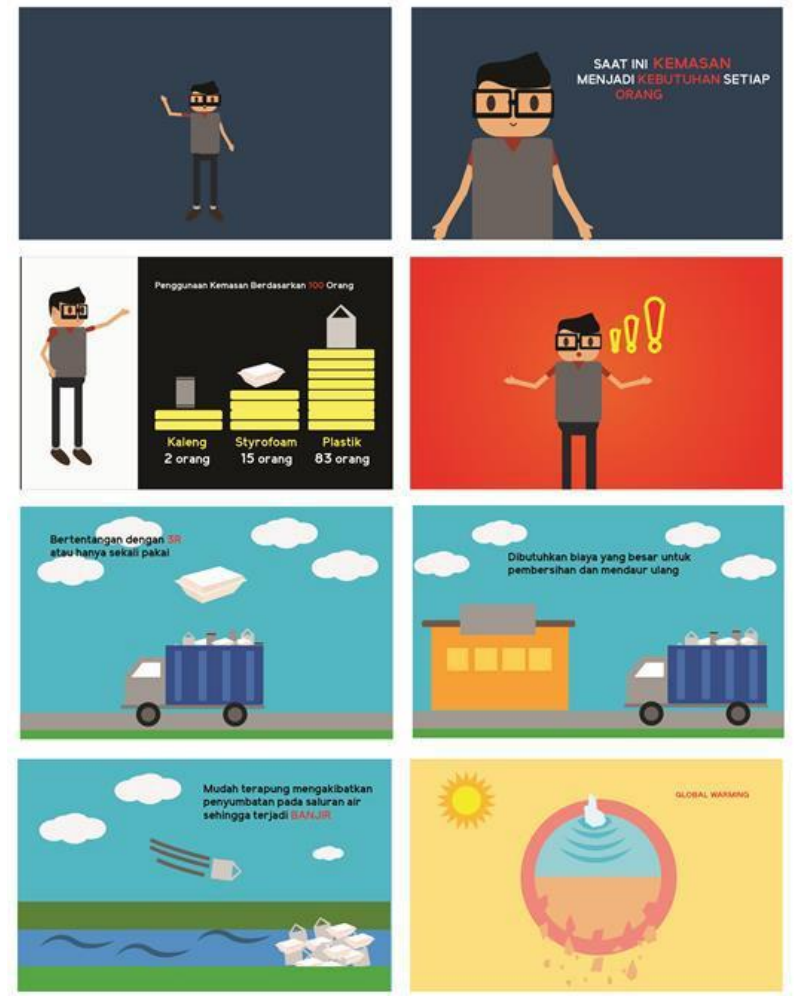

Figure 1. Storyboard of Motion Graphic

\section{Conclusion}

Today many food and beverage sellers still use hazardous food packaging (e.g. styrofoam). There is the lack of understanding of both sellers and consumers about the packaging that has a bad impact on the environment and health. Various programs conducted in the approach to the community to introduce eco-packaging has been done. Campaign through motion graphic could be efective depends on target audiences. Billboard or megatron screen could be effective media that many people can see and receive the content of the information provided. Motion graphic in this case could communicate the message to create a visual and emotional allure that persuades target audiences.

This study is concern about the motion graphic for megatron screen yet target audiences nowadays are more engage with social media. For further research, it is interesting to study about the impact of megatron screen to persuade target audiences compare to social media i.e. you tube channel. 


\section{ACKNOWLEDGEMENT}

Authors would like to thanks to Department of Environment and Hygiene especially to Mr. Septriadi Pratama and Mr. Enry Rahmadi Efriansyah as interviees.

\section{REFERENCES}

[1] A. Kapoor. (2016). Packaging Special: A Vision for Eco-Friendly Packaging. [Online] Available at: http://fmtmagazine.in/packaging-special-a-vision-for-eco-fri endly-packaging/ [Accessed 6/2/2017].

[2] M. R. Klimchuk \& S. A. Krasovec, DESAIN KEMASAN. 1st ed. Jakarta: Erlangga, 2006.

[3] Rajasundaram, 1981 in A. Venus, Manajeman Kampanye : Panduan Teoritis dan Praktis dalam mengefektifkan kampanye Komunikasi. 3th ed. Bandung: Simbiosa Rekatama, 2004.

[4] I. Macdonald, Designing to engage a television audience: how are different media used in TV ident creation? Arts Marketing, 5(2), pp. 139-153, 2015. Available: https://search.proquest.com/docview/1899124378?accountid $=31562$

[5] J. Lankow, J. Ritchie, \& R. Crooks, Infografis: Kedasyatan Cara Bercerita Visual. 1st ed. Jakarta: PT Gramedia Pustaka Utama, 2014.

[6] S. Pratama, in-depth interview, 2017.

[7] E.R. Efriansyah, in-depth interview, 2017. 